\title{
Pediatric obesity: life cycle approach of pediatrician and society
}

Yong Hee Hong MD, PhD

Department of Pediatrics, Soonchunhyang University Bucheon Hospital, Soonchunhyang University School of Medicine, Bucheon, Korea

\section{Key message}

- With the emerging epidemic of pediatric obesity, many endocrine comorbidities classically seen in adulthood are surfacing much earlier in life.

- Appropriate obesity counseling and education should be provided from infancy to adolescence.

- Managing pediatric obesity may require school and society involvement.

The prevalence of obesity in children has increased significantly during the past few decades. The related behavioral and environmental factors have been negatively impacted by the coronavirus disease 2019 (COVID-19) pandemic, including losses of daily routines. Obesity in children may further increase in the future, and some countries have already reported increased pediatric obesity rates. ${ }^{1)}$

At this point, obesity counseling by age group is necessary (Fig. 1). Small for gestational age (SGA) and large for gestational age (LGA) size at birth are associated with body adiposity and metabolic complications throughout life. ${ }^{2)}$ Children who are born SGA also experience weight acceleration, while those born LGA experience an absence of weight deceleration; both states have been associated with future obesity. ${ }^{3)}$ Many observational studies have suggested that rapid weight gain in infancy (upward centile crossing) increases an individual's long-term risk of obesity. ${ }^{4)}$ The optimal infant weight gain pattern may differ depending on birth weight regardless of preterm versus term status. Pediatricians should consider birth weight, a prenatal determinant of obesity and catch-up and -down growth, in obesity counseling.

Adiposity rebound (AR) in early childhood is a risk factor for obesity and metabolic derangement in adolescence and adulthood. Body mass index rapidly increases during the first year of life, then subsequently decreases and reaches a nadir at around 6 years of age. Thereafter, it increases again throughout childhood, a phenomenon termed AR. ${ }^{5)}$ The close relationship between an early AR timing and later obesity is well known. ${ }^{5}$ Moon $^{6}$ recently reported that a late AR timing was significantly associated with a decreased risk of developing obesity and an increased probability of reversing obesity among kindergarteners. Therefore, pediatricians should be able to educate parents and children on the dangers of an early AR.

Childhood obesity is caused by a combination of genetic and

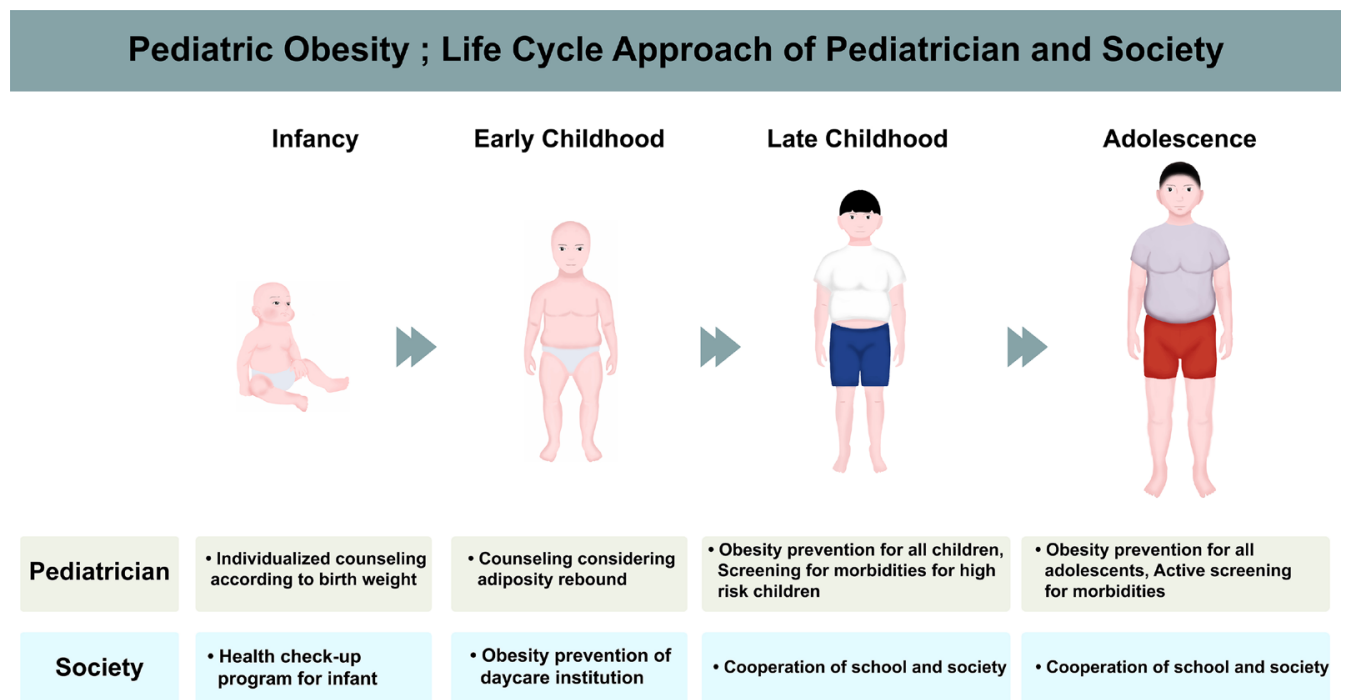

Fig. 1. Pediatric obesity: life cycle approach of pediatrician and society. 
epigenetic factors as well as environmental and behavioral factors such as nutrition and physical activity. Since school-aged children spend a lot of time at school, it is necessary to create a social environment and atmosphere in which they are allowed to move. Schools can play a role in preventing childhood obesity by serving healthy meals with adequate calories and nutrients, providing nutrition education that encourages healthy food selection, offering opportunities for physical activity, and creating environments that model healthy behaviors.) Obesity management at this time requires school and societal involvement. In this age group, education on obesity prevention should be provided to children attending pediatric clinics whenever possible. In addition, a national health insurance policy should be implemented.

Growing evidence shows that the prevalence of severe obesity is increasing in adolescents in several countries, including Korea. ${ }^{8)}$ The spontaneous remission of obesity to a healthy weight is rare; at least $90 \%$ of obese adolescents will be overweight or obese in young adulthood.9) Adolescence represents a critical time to set one's habits for long-term health. ${ }^{10)}$ Therefore, preventing and treating adolescent obesity are important.

The increasing prevalence of childhood and adolescent obesity is associated with an increase in comorbidities previously identified in the adult population, such as type 2 diabetes mellitus, hypertension, nonalcoholic fatty liver disease, and dyslipidemia. ${ }^{11)}$ In a recent issue of Clinical and Experimental Pediatrics, Lee and $\mathrm{Kim}^{12)}$ reviewed the endocrine comorbidities of pediatric obesity. The authors showed increasing trends of endocrine comorbidities of obesity and emphasized that maintaining a healthy weight and preventing obesity are of critical importance. The high rates of childhood and adolescent obesity and related endocrine comorbidities, which were recently exacerbated by the COVID-19 pandemic, require awareness of obesity prevention, screening for comorbidities, and developing treatment strategies for high-risk children.

In conclusion, with the emerging epidemic of pediatric obesity, many endocrine comorbidities classically seen in adulthood are surfacing much sooner in life. Appropriate obesity counseling and education should be provided from infancy to adolescence.

See the article "Endocrine comorbidities of pediatric obesity" via https://doi.org/10.3345/cep.2021.00213

\section{Footnotes}

Conflicts of interest: No potential conflict of interest relevant to this article was reported.

ORCID:

Yong Hee Hong @ https://orcid.org/0000-0002-4676-8483

\section{References}

1. Stavridou A, Kapsali E, Panagouli E, Thirios A, Polychronis K, Bacopoulou $\mathrm{F}$, et al. Obesity in children and adolescents during COVID-19 pandemic. Children (Basel) 2021;8:135.

2. Hong YH, Lee JE. Large for gestational age and obesity-related comor bidities. J Obes Metab Syndr 2021;30:124-31.

3. Lyons-Reid J, Albert BB, Kenealy T, Cutfield WS. Birth size and rapid infant weight gain-where does the obesity risk lie? J Pediatr 2021;230: 238-43.

4. Singhal A. Long-term adverse effects of early growth acceleration or catch-up growth. Ann Nutr Metab 2017;70:236-40.

5. Kang MJ. The adiposity rebound in the 21 st century children: meaning for what? Korean J Pediatr 2018;61:375-80.

6. Moon RC. Late adiposity rebound and the probability of developing and reversing childhood obesity. J Pediatr 2020;216:128-35.

7. Harrison MK, Peggs C. The role of schools in preventing childhood obesity. W V Med J 2002;98:260-62.

8. Nam HK, Kim HR, Rhie YJ, Lee KH. Trends in the prevalence of extreme obesity among Korean children and adolescents from 2001 to 2014. J Pediatr Endocrinol Metab 2017;30:517-23.

9. Patton GC, Coffey C, Carlin JB, Sawyer SM, Williams J, Olsson CA, et al. Overweight and obesity between adolescence and young adulthood: a 10year prospective cohort study. J Adolesc Health 2011;48:275-80.

10. Vajravelu ME, Arslanian S. Mobile health and telehealth interventions to increase physical activity in adolescents with obesity: a promising approach to engaging a hard-to-reach population. Curr Obes Rep 2021 Oct 1:1-9. https://doi.org/10.1007/s13679-021-00456-8. [Epub].

11. Kansra AR, Lakkunarajah S, Jay MS. Childhood and adolescent obesity: a review. Front Pediatr 2021;8:581461.

12. Lee J, Kim JH. Endocrine comorbidities of pediatric obesity. Clin Exp Pediatr 2021;64:619-27.

How to cite this article: Hong YH. Pediatric obesity: life cycle approach of pediatrician and society. Clin Exp Pediatr 2022;65:29-30. https://doi.org/10.3345/cep.2021.01536 